of entropy. On p. 62 the following statement appears : "The entropy of a given quantity of gas is defined as the ratio of its total heat to its absolute temperature. Thus, Entropy $\varphi=H / T$, where $H=$ total heat reckoned from a given datum level, e.g., absolute zero, and $T=$ absolute temperature". This is a mis. conception of the first magnitude which must be pointed out, as this book is likely to come into the hands of students whose imagination has been fired by the rapid development of the gas turbine, and whose knowledge of thermodynamies may not be sufficient to detect such errors. There are other errors in the text which make the chapter on thermodynamics unreliable.

However, the book improves when the author confines himself to descriptive work, the chapter on aircraft propulsion being very well done and containing some excellent illustrations.

It seems a pity that more emphasis was not placed on the vast difference between the aircraft gas turbine on one hand, and the land or marine gas turbine on the other. The design of the latter type of machine is a much more difficult proposition than that of the former, both because of the thermodynamic problems involved in converting the kinetic energy of the jet into useful work, and the metallurgical problems involved in finding materials to withstand the working temperatures, not for 500-1,000 hours as in the case of the aircraft turbine, but for ten to twenty years.

The book could serve a useful purpose if some of the errors, particularly in the chapters on thermodynamics, were corrected. One of the most useful features is the bibliography containing eighty-nine references.

E. G. StrerLaND

\section{CHEMICAL ENGINEERING}

\section{Chemical Engineering Fundamentals}

By Chalmer G. Kirkbride. (McGraw-Hill Chemical Engineering Series.) Pp. xi+419. (New York and London: McGraw-Hill Book Co., Inc., 1947.) 30s.

1 HE intention of this book is to enable students with little knowledge of chemistry and mathematics and none of physical chemistry to begin the study of chemical engineering, or rather of what are termed "the five technical fundamentals". It opens with a chapter on human relations in chemical engineering; the next deals with "Useful Mathematical Tools". This is followed by "Important Concepts of Physics and Chemistry"-in fifty pages. Of these it might be said that never were so many facts (sometimes not strictly accurate) compressed into so few pages. The effect of reading this part of the book is one of bewilderment and a feeling of agreement with a statement made later that "dogmatism usually irritates most readers". It is doubtful if British students, who are trained to think rather than absorb facts, could take in all that is presented, or if it would be of any value to them if they did. They might well gain the impression, for example, that there are five important aromatic compounds represented by well-drawn formulæ, one of which, styrene, is used to make synthetic rubber. Whether it is a solid, liquid, or gas is apparently immaterial, as are its chemical reactions, other than polymerization.

Apart from this too intensive matter, there are many features in the book which are original and of much value to the discriminating teacher. The chapters on material balance, energy balance, static equilibria, dynamic equilibria and economic balance (though what balances in this case is not clear) are by no means elementary and contain numerous illustrative examples. The first and last chapters, on human relations in chemical engineering and the presentation of technical reports respectively, deal with subjects now recognized as of vital importance and, if not taken too literally, may be read with great advantage not only by teachers but also by those actually engaged in industry. The fifty pages of appendix with fifteen tables and twenty-nine graphs might have been more usefully devoted to the explanation of some of the statements in Chapter 3.

H. E. WATSON

\section{RIVERS-A NATIONAL HERITAGE}

\section{Our Rivers}

By J. W. Kempster. Pp. $x i+300+21$ plates. (London, New York and Toronto : Oxford University Press, 1948.) 25s. net.

T IFE in Great Britain, while not at first sight 1 greatly influenced by rivers, in actuality is very profoundly affected by them. At one time the rivers were far more than a convenient means of disposal of sewage, and there is an increasing deepening of interest in the restoration of the rivers to something like their pre-industrial condition. Government departments which are greatly interested in these matters include the Ministry of Agriculture and Fisheries (with wide interests in fishing and in the irrigation of farm lands), the Ministry of Health (which watches zealously those rivers which are used for water supplies to the public), the Department of Scientific and Industrial Research (which is interested in water pollution research, and also in the hydraulies), the Ministry of Transport (on account of inland transport, water power, and the dangers of pollution from tarred roads), and many others. Obviously the subject is one that is important to the engineers of towns and cities and to civil engineers in general in relation to land drainage.

The author of this book has dealt comprehensively, if briefly, with all aspects of the matter. As an angler he holds that migratory fish are the best judges of pure water, and he commences by dealing with the life-history of salmon and sea trout. As a natural development he then takes up the subject of obstructions in the rivers, and devotes a chapter to river management, and another one to pollution. There follow several chapters dealing with legislation affecting rivers, and these appear to be of very great value as they cover the activities of the various bodies entrusted by Parliament with the management and control of rivers; and the over-riding Acts of Parliament are summarized. Fifteen appendixes give a mine of varied information in compact form.

The author is an enthusiast on the subject of improvements in the rivers of Britain. He regards them as a national heritage, and seeks to enlist interest and support towards conserving their utility, natural beauty and enchantment. The book is commended to all who are like-minded.

A. T. Doodson 